\title{
INOCULAÇÃO DE SEMENTES DE CORNICHÃO (Lotus corniculatus) E ERVILHACA (Vicia sativa) NA PRESENÇA E AUSÊNCIA DE CALCÁRIO
}

\author{
Seed Inoculation of Birdsfoot Trefoil (Lotus corniculatus) and of Common \\ Vetch (Vicia sativa) with and without Limestone
}

\author{
Flora Osaki \\ Agrônoma, M. Sc., Prof. ${ }^{a}$ da PUCPR, Curitiba - PR. e-mail: rk_osaki@netpar.com.br \\ Marcel Negrelo \\ Aluno de Agronomia, Curitiba - PR. e-mail: rk_osaki@netpar.com.br
}

\section{Resumo}

A baixa disponibilidade de forragem durante o inverno para o gado tem sido o fator de maior limitação na produção de carne, leite e outros produtos animais. O presente trabalho teve por objetivo avaliar a contribuição da calagem e da inoculação de sementes de cornichão e ervilhaca na produção de biomassa e do teor de $\mathrm{N}$ nas plantas. O trabalho foi realizado na Miniestação Experimental da PUCPR, em São José dos Pinhais, PR. O delineamento utilizado foi o de blocos ao acaso em arranjo fatorial $2 \times 2 \times 2$, duas espécies leguminosas, ausência e presença de calcário e ausência e presença de inoculante, com quatro repetições. As amostras foram coletadas em duas épocas, identificadas e encaminhadas ao Laboratório de Análise. Os resultados foram submetidos à análise de variância e comparados pelo teste de Tukey a 5\%. Os resultados mostraram que no primeiro corte o teor de nitrogênio foi superior para a ervilhaca na presença de calcário e sem inoculante, quando comparado ao cornichão. A produção de matéria seca foi superior para a ervilhaca, tanto na ausência, como na presença de calcário, no primeiro corte. A ervilhaca apresentou maior produção de matéria seca na ausência de inoculante, enquanto que para o cornichão a maior produção foi verificada na presença de inoculante. No segundo corte, o teor de nitrogênio foi superior no tratamento com inoculante para o cornichão. Para o cornichão, foi verificado maior teor de $\mathrm{N}$ na presença de calcário, no segundo corte. No segundo corte, na ausência de calcário, o teor de $\mathrm{N}$ foi superior na presença de inoculante. A produção de matéria seca do cornichão foi superior ao da ervilhaca, tanto na presença quanto na ausência de inoculante, para o segundo corte. A ervilhaca apresentou a maior produção de matéria seca na ausência de calcário, mas não diferiu daquela obtida para o cornichão. No segundo corte, a produção de matéria seca foi superior na presença do inoculante e na ausência de calcário.

Palavras-chave: Cornichão; Ervilhaca; Inoculante; Calagem; Pastagem. 


\section{Abstract}

The low availability of forage for the animals during the winter has been the most important factor limiting the production of beef, milk and other animal products. This work was conducted, at Mini Experimental Station of PUCPR in São José dos Pinhais, PR, to evaluate the contribution of limestone fertilization and seed inoculation with rhizobia of Lotus corniculatus e Vicia sativa upon production of biomass and $N$ content in the plants. The experimental design was a $2 \times 2 \times 2$ factorial (two forage species; with and without limestone; and, with and without inoculation) arranged in completely randomized blocks with four replicates. Samples were taken at two different times (cuts), identified and sent to laboratory for analyses. Data were submitted to analysis of variance and means were compared by Tukey test at 5\% level of probability. The results showed that in the first cut the $N$ content of $V$. sativa with limestone and without inoculation was higher in comparison to L. corniculatus. Dry matter production was higher for $V$. sativa in both the presence as well as in the absence of limestone. $V$. sativa yielded more dry matter when seeds were not inoculated, whereas for L. corniculatus the highest production was observed in the presence of seed inoculation. In the second cut, $N$ content was superior for L. corniculatus with seed inoculation and limestone fertilization. In the second cut, in the absence of limestone, $N$ content was superior when seeds were inoculated. The production of dry matter of L. corniculatus was superior to that of $V$. sativa for both, with and without inoculation, in the second cut. $V$. sativa yielded the highest production of dry matter in the absence of limestone, but with no difference from that obtained for L. corniculatus. In the second cut, the production of dry matter was superior with seed inoculation and without limestone.

Keywords: L. corniculatus; V. sativa; Inoculation; Limestone; Pastures.

\section{INTRODUÇÃO}

Uma das atividades econômicas de maior importância no Brasil é a pecuária e a área de pastagem cultivada atinge cerca de 115 milhões de hectares, enquanto que a pastagem nativa conta com 144 milhões de hectares (VILELA, 2005).

A produção de pastagens, seja nativa ou cultivada, apresenta como limitação a variação na disponibilidade de forragem, verificando-se ao longo do ano um ciclo de maior produção de forragem e outro de menor produção (UFRGS, 2005).

O desafio de qualquer sistema de produção é o de manejar este ciclo de oferta. A utilização de espécies de inverno, programas de fertilização do solo, calagem e fenação são algumas das alternativas para reduzir o déficit na oferta de alimento (UFRGS, 2005).

A utilização de leguminosas de inverno pode resultar na melhoria de oferta de forragem nos períodos de escassez. Além disso, devido à capacidade de fixação de nitrogênio, melhoram a qualidade do solo.

Entre as leguminosas, o cornichão (Lotus corniculatus L.) apresenta boa cobertura de solo, podendo ser associado a outras espécies, ressemeando naturalmente. Pode ser usado como forrageira, pois é tenro, palatável e nutritivo (PUPO, 1995). É uma planta forrageira de muita utilidade no Sul, recomendada para pastagens permanentes em regiões temperadas e sua produção é de 15 a 19 t/ha (ALCÂNTARA et al., 1992). Moraes (1995) recomenda a inoculação de sementes, caso contrário a cultura vai se mostrar tardia nos primeiros meses e com pouca capacidade de rebrote nos primeiros anos de utilização.

Outra leguminosa de interesse forrageiro é a ervilhaca (Vicia sativa), que apresenta inúmeras vantagens, como adubo verde ou forragem de inverno (COSTA et al. 1993). Sua produção de massa verde está em torno de 20 a 28 t/ha (ALCÂNTARA et al., 1992).

Para se obter bom rendimento no cultivo do cornichão e da ervilhaca, é recomendada a inoculação das sementes com bactérias específicas, principalmente em áreas de primeiro cultivo (COSTA et al., 1993). 
Para o cornichão (Lotus corniculatus), a bactéria específica é a Rhiøobium loti; para a ervilhaca (Vicia sativa), a bactéria é a Rhizobium leguminosarum (TURFAL).

O uso de inoculante é vantajoso pelo fato de ter alta concentração de células, dispensa o uso de adubos nitrogenados, aumenta a produtividade, maior rendimento de proteína na massa verde, enriquece o solo com nitrogênio fixado, é um insumo de baixo custo, maior custo/benefício e é um produto biológico que não agride o meio ambiente (TURFAL).

Entre os fatores que influenciam a produção de forragens inclui-se ainda a calagem. Esta prática em pastagens, na maioria das vezes, não é contemplada. A falta de compromisso do produtor em manter a qualidade do solo, a grande extensão de áreas na qual é desenvolvida e a falsa impressão de redução nos custos são algumas das causas de falta de utilização deste corretivo (OSAKI, 1991; PAVAN; OLIVEIRA, 1997).

As correções e fertilizações químicas nem sempre são adequadas ao solo/clima/planta, razão pela qual tem sua resistência reduzida frente a períodos de seca, frio (geadas), tornando-se mais fracas e suscetíveis a doenças e pragas (THUNG; OLIVEIRA, 1998; MARUN; ALVES, 1996).

No Paraná, a acidez do solo, indicada pela presença de $\mathrm{Al}^{3+}$ trocável, não é um problema localizado. Está presente na maioria das regiões agrícolas. Os solos são naturalmente ácidos ou tornamse progressivamente ácidos em conseqüência do manejo inadequado. A correção do pH deve visar 3 pontos: aumentar o complexo de troca, isto é, influir sobre a CTC dependente de $\mathrm{pH}$; saturar o complexo de troca com cálcio, elevar o $\mathrm{pH}$ até um nível que o alumínio trocável não prejudique mais, o que ocorre a um $\mathrm{pH}$ de 5,5 .

Entre as leguminosas, as diferenças de resposta à calagem são mais acentuadas, existindo espécies/cultivares consideradas muito sensíveis à acidez. Numerosos trabalhos têm demonstrado que a aplicação de calcário pode favorecer a simbiose rizobium-leguminosa, aumentando a nodulação e a fixação de nitrogênio (MARUN; ALVES, 1996).

Este trabalho teve por objetivos avaliar a contribuição da inoculação de sementes e da prática de calagem na produção de biomassa de ervilhaca e cornichão.

\section{MATERIAL E MÉTODOS}

O trabalho foi desenvolvido a campo na Miniestação Experimental e em Laboratório de Análise de Solos e Nutrição Mineral de Plantas pertencentes à Pontifícia Universidade Católica do Paraná, Câmpus São José dos Pinhais. O clima da região, de acordo com Koëppen, é classificado como Cfb (IAPAR, 1994).

O delineamento experimental utilizado foi o de blocos ao acaso, com parcelas subdivididas, em arranjo fatorial $2 \times 2 \times 2$ (duas espécies - ervilhaca e cornichão; com e sem inoculante, com e sem calcário), tendo os tratamentos com e sem calcário no nível de parcelas e os tratamentos ervilhaca com e sem inoculação e cornichão com e sem inoculante no nível de subparcelas, com quatro repetições.

A área da parcela foi de $4,0 \mathrm{~m}^{2}$ e a área total de $200 \mathrm{~m}^{2}$.

A semeadura foi feita a lanço; as densidades utilizadas foram de $80 \mathrm{~kg} / \mathrm{ha} \mathrm{e} 8 \mathrm{~kg} / \mathrm{ha}$ para a ervilhaca e cornichão, respectivamente. A inoculação das sementes foi realizada com inoculante turfoso. Para o cornichão (Lotus corniculatus), foi utilizada a bactéria Rhizobium loti e para a ervilhaca (Vicia sativa) a bactéria Rhizobium leguminosarum (TURFAL).

O inoculante turfoso foi dissolvido em $300 \mathrm{ml}$ de solução açucarada a 10\%, em uma proporção de $100 \mathrm{~g}$ de inoculante para $8 \mathrm{~kg}$ de sementes, despejando a solução nas sementes e misturando bem até a cobertura total das sementes e, em seguida, foram secadas à sombra. A semeadura foi feita no mesmo dia da inoculação.

A aplicação de calcário foi realizada 30 dias antes da semeadura, na dose de $3 \mathrm{t} / \mathrm{ha}$, determinado pelo método de saturação de bases e apresentava PRNT de $85 \%$.

As amostras foram coletadas de todas as plantas de uma área de 0,25 $\mathrm{m}^{2}$, em três pontos de uma mesma parcela, aos 120 dias após a emergência das plântulas. A altura de corte foi de 5,0 cm acima 
do solo, condicionados em sacos plásticos, identificados e conduzidos ao laboratório. A determinação da biomassa foi realizada conforme Lenkeit e Becker (1956). A extração do nitrogênio foi feita por meio da digestão ácida a quente (digestão sulfúrica, ácido sulfúrico, nitrogênio-N) e o método utilizado foi o Semimicro-Kjeldahl (MALAVOLTA et al., 1989).

\section{RESULTADOS E DISCUSSÃO}

$\mathrm{Na}$ Tabela 1 estão apresentados os resultados para o teor de $\mathrm{N}$ nas duas espécies forrageiras, na presença e ausência de inoculante e na presença e ausência de calcário, para o primeiro corte.

TABELA 1 - Teor de N (kg/ha) de duas espécies forrageiras, ervilhaca e cornichão, na presença e ausência de inoculante e na presença e ausência de calcário - $1^{\circ}$ corte

Table 1 - Content of N (k.g/ha) of two forage species, Common Vetch and Birdsfoot Trefoil, in presence or absence of inoculants and in presence or absence of calcareous - cut 1

\begin{tabular}{l|c|c|c|c}
\hline & $\begin{array}{c}\text { Com Inoculante } \\
\mathrm{kg} / \mathrm{ha}\end{array}$ & $\begin{array}{c}\text { Sem inoculante } \\
\mathrm{kg} / \mathrm{ha}\end{array}$ & $\begin{array}{c}\text { Com calcírio } \\
\mathrm{kg} / \mathrm{ha}\end{array}$ & $\begin{array}{c}\text { Sem calcírio } \\
\mathrm{kg} / \mathrm{ha}\end{array}$ \\
\hline Ervilhaca & $344,36 \mathrm{a} \mathrm{A}$ & $504,96 \mathrm{~b} \mathrm{~A}$ & $530,38 \mathrm{a} \mathrm{A}$ & $318,94 \mathrm{~b} \mathrm{~A}$ \\
Comichão & $256,82 \mathrm{a} \mathrm{B}$ & $254,11 \mathrm{a} \mathrm{B}$ & $287,57 \mathrm{a} \mathrm{B}$ & $223,35 \mathrm{a} \mathrm{B}$ \\
\hline DMS & \multicolumn{2}{c}{22,00} \\
\hline
\end{tabular}

Médias seguidas pela mesma letra, maiúsculas na vertical e minúsculas na horizontal, não diferem pelo Teste de Tukey a $5 \%$.

Observa-se, na Tabela 1, que a ervilhaca apresentou maior quantidade de nitrogênio que o cornichão, independente da presença ou ausência do inoculante.

Quando consideradas as espécies individualmente, observa-se que não houve diferenças estatisticamente significante para o cornichão e que a ervilhaca apresentou maior quantidade de $\mathrm{N}$, na ausência do inoculante para o teor de nitrogênio.

Observa-se, na Tabela 1, que a ervilhaca apresentou maior quantidade de nitrogênio que o cornichão, independente da presença ou ausência do calcário.

Quando consideradas as espécies individualmente, observa-se que a ervilhaca apresentou maior quantidade $\mathrm{N}$ na presença de calcário, enquanto o cornichão não apresentou diferença estatisticamente significativa (TABELA 1).

TABELA 2 - Teor de N (kg/ha) na presença e ausência de inoculante e presença e ausência de calcário $-1^{\circ}$ corte.

Table 2 - Content of $N(\mathrm{~kg} / \mathrm{ha})$ in presence or absence of inoculants and in presence or absence of calcareous - cut 1

\begin{tabular}{l|c|c}
\hline & Com inoculante & Sem inoculante \\
\hline Com calcírio & $330,36 \mathrm{~b} \mathrm{~A}$ & 487,59 a A \\
Sem calcário & $270,82 \mathrm{a} \mathrm{B}$ & 271,47 a B \\
\hline DMS & & 22,00 \\
\hline
\end{tabular}

Médias seguidas pela mesma letra, maiúsculas na vertical e minúsculas na horizontal, não diferem pelo Teste de Tukey a $5 \%$. 
Observa-se, na Tabela 2, que a maior quantidade de nitrogênio foi verificada no tratamento com calcário e sem inoculante e na ausência de calcário não houve diferença estatística significativa quando estudada a presença ou ausência do inoculante.

As Tabelas 3 e 4 apresentam a produção de matéria seca $(\mathrm{kg} / \mathrm{ha})$ para os diferentes tratamentos estudados no primeiro corte.

TABELA 3 - Produção de matéria seca (kg/ha) de duas espécies forrageiras, ervilhaca e cornichão, na presença e ausência de inoculante e na presença e ausência de calcário - $1^{\circ}$ corte

Table 3 - Dry matter production $(\mathrm{kg} / \mathrm{ha})$ of two forage species, Common Vetch and Birdsfoot Trefoil, in presence or absence of inoculants and in presence or absence of calcareous - cut 1

\begin{tabular}{l|c|c|c|c}
\hline & $\begin{array}{c}\text { Com Inoculante } \\
\mathrm{kg} / \mathrm{ha}\end{array}$ & $\begin{array}{c}\text { Sem inoculante } \\
\mathrm{kg} / \mathrm{ha}\end{array}$ & $\begin{array}{c}\text { Com calcírio } \\
\mathrm{kg} / \mathrm{ha}\end{array}$ & $\begin{array}{c}\text { Sem calcsírio } \\
\mathrm{kg} / \mathrm{ha}\end{array}$ \\
\hline Ervilhaca & $1464,3 \mathrm{bA}$ & $1608,0 \mathrm{aA}$ & $1615,9 \mathrm{a} \mathrm{A}$ & $1456,4 \mathrm{~b} \mathrm{~A}$ \\
Comichāo & $1297,6 \mathrm{a} \mathrm{B}$ & $1228,3 \mathrm{~b} \mathrm{~B}$ & $1263,4 \mathrm{a} \mathrm{B}$ & $1262,5 \mathrm{a} \mathrm{B}$ \\
\hline DMS & \multicolumn{2}{c}{64,56} \\
\hline
\end{tabular}

Médias seguidas pela mesma letra, maiúsculas na vertical e minúsculas na horizontal, não diferem pelo Teste de Tukey a $5 \%$.

Observa-se, na Tabela 3, que a produção de matéria seca pela ervilhaca foi superior e estatisticamente diferente daquela produzida pelo cornichão, independente da presença ou ausência do inoculante.

Quando consideradas as espécies individualmente, observa-se que o cornichão foi superior e estatisticamente diferente na produção de matéria seca com inoculante. Para a ervilhaca, na ausência de inoculante, foi verificada maior produção de matéria seca, diferindo estatisticamente do tratamento com inoculante (TABELA 3).

Observa-se, na Tabela 3, para a presença e ausência de calcário, que a ervilhaca apresentou maior quantidade de matéria seca, diferindo estatisticamente do cornichão.

Quando consideradas as espécies individualmente, observa-se que a ervilhaca apresentou maior quantidade de matéria seca na presença de calcário, enquanto o cornichão não apresentou diferença estatisticamente significativa na presença ou ausência de calcário (TABELA 3).

TABELA 4 - Produção de matéria seca (kg/ha) de duas espécies forrageiras, ervilhaca e cornichão, na presença e ausência de inoculante e presença e ausência de calcário $-1^{\circ}$ corte

Table 4 - Dry matter production $(\mathrm{kg} / \mathrm{ha}$ ) of two forage species, Common Vetch and Birdsfoot Trefoil, in presence or absence of inoculants and in presence or absence of calcareous - cut 1

\begin{tabular}{l|c|c}
\hline & Com inoculante & Sem inoculante \\
\hline Com calcário & $1331,1 \mathrm{~b} \mathrm{~A}$ & $1548,2 \mathrm{a} \mathrm{A}$ \\
Sem calcário & $1430,8 \mathrm{a} \mathrm{B}$ & $1288,1 \mathrm{~b} \mathrm{~B}$ \\
\hline DMS & & 64,56 \\
\hline
\end{tabular}

Médias seguidas pela mesma letra, maiúsculas na vertical e minúsculas na horizontal, não diferem pelo Teste de Tukey a $5 \%$. 
Observa-se, na Tabela 4, que a maior quantidade de matéria seca foi verificada no tratamento com calcário e sem inoculante.

Quando se considera a ausência de calcário, observa-se na Tabela 4 que a maior produção de matéria seca foi alcançada na presença do inoculante, diferindo estatisticamente do tratamento sem inoculante.

Nas Tabelas 5 e 6 estão apresentados os resultados obtidos para o teor de nitrogênio obtido no segundo corte para as culturas de ervilhaca e cornichão na presença e ausência de inoculante e na presença e ausência de calcário.

TABELA 5 - Teor de N (kg/ha) de duas espécies forrageiras, ervilhaca e cornichão, na presença e ausência de inoculante e na presença e ausência de calcário - $2^{\circ}$ corte

Table 5 - Content of N (kg/ha) of two forage species, Common Vetch and Birdsfoot Trefoil, in presence or absence of inoculants and in presence or absence of calcareous - cut 2

\begin{tabular}{l|c|c|c|c}
\hline & $\begin{array}{c}\text { Com inoculante } \\
\mathrm{Kg} / \mathrm{ha}\end{array}$ & $\begin{array}{c}\text { Sem inoculante } \\
\mathrm{Kg} / \mathrm{ha}\end{array}$ & $\begin{array}{c}\text { Com calcário } \\
\mathrm{Kg} / \mathrm{ha}\end{array}$ & $\begin{array}{c}\text { Sem calcírio } \\
\mathrm{Kg} / \mathrm{ha}\end{array}$ \\
\hline Ervilhaca & $548,93 \mathrm{a} \mathrm{B}$ & $520,42 \mathrm{a} \mathrm{A}$ & $455,49 \mathrm{~b} \mathrm{~B}$ & $613,85 \mathrm{a} \mathrm{A}$ \\
Comichão & $837,84 \mathrm{a} \mathrm{A}$ & $573,64 \mathrm{~b} \mathrm{~A}$ & $848,46 \mathrm{a} \mathrm{A}$ & $563,02 \mathrm{~b} \mathrm{~A}$ \\
\hline DMS & \multicolumn{3}{c}{$67,64,64$} \\
\hline
\end{tabular}

Médias seguidas pela mesma letra, maiúsculas na vertical e minúsculas na horizontal, não diferem pelo Teste de Tukey a $5 \%$.

Observa-se, na Tabela 5, que o cornichão apresentou maior quantidade de $\mathrm{N}$ que a ervilhaca na presença do inoculante. Quando considerada a ausência de inoculante, não houve diferenças estatísticas entre as duas espécies estudadas.

Quando considerada a presença e a ausência de inoculante para a ervilhaca, não foram observadas diferenças estatísticas significativas. Para a cultura do cornichão, observou-se maior quantidade de nitrogênio para o tratamento com inoculante.

No segundo corte, observa-se na Tabela 5 que a ervilhaca apresentou maior quantidade de nitrogênio na ausência do calcário, diferindo estatisticamente do tratamento com calcário. Para a espécie forrageira cornichão, o maior teor de N é verificado no tratamento com calcário. Para o segundo corte, o cornichão apresentou maior quantidade de $\mathrm{N}$, diferindo estatisticamente da ervilhaca.

Comparando as espécies dentro dos tratamentos presença e ausência de calcário, verifica-se maior teor de $\mathrm{N}$ para o cornichão no tratamento com calcário. Na ausência de calcário, as espécies não apresentaram diferenças estatísticas (TABELA 5).

TABELA 6 - Teor de N (kg/ha) de duas espécies forrageiras, ervilhaca e cornichão, na presença e ausência de inoculante e presença e ausência de calcário, $2^{\circ}$ corte Table 6 - Content of N (kg/ha) of two forage species, Common Vetch and Birdsfoot Trefoil, in presence or absence of inoculants and in presence or absence of calcareous - cut 2

\begin{tabular}{l|c|c}
\hline & Com inoculante & Sem inoculante \\
\hline Com calcírio & 713,42 a A & 673,35 a A \\
Sem calcário & 590,54 a B & $503,52 \mathrm{~b} \mathrm{~B}$ \\
\hline DMS & & 67,64 \\
\hline
\end{tabular}

Médias seguidas pela mesma letra, maiúsculas na vertical e minúsculas na horizontal, não diferem pelo Teste de Tukey a 5\%. 
Observa-se, na Tabela 6, que na presença de calcário, o teor de $\mathrm{N}$ na presença ou ausência de inoculante não foram estatisticamente diferentes. Na ausência de calcário, o maior teor de $\mathrm{N}$ foi verificado para o tratamento com inoculante, diferindo estatisticamente do tratamento sem inoculante.

Quando consideradas a média dos dois níveis de calcário, o teor de N mostrou-se superior na presença do calcário e estatisticamente diferente do tratamento sem calcário (TABELA 6).

Considerando o efeito do calcário na presença e ausência do inoculante, verifica-se que a presença de calcário resultou em maior teor de $\mathrm{N}$, diferindo estatisticamente do tratamento sem calcário (TABELA 6).

Nas Tabelas 7 e 8 são apresentados os resultados obtidos para a produção de matéria seca para o segundo corte, para as culturas de ervilhaca e cornichão na presença e ausência de inoculante e na presença e ausência de calcário.

TABELA 7 - Produção de matéria seca (kg/ha) de duas forrageiras, ervilhaca e cornichão, na presença e ausência de inoculante e na presença e ausência de calcário $-2^{\circ}$ corte Table 7 - Dry matter production $(\mathrm{kg} / \mathrm{ha}$ ) of two forage species, Common Vetch and Birdsfoot Trefoil, in presence or absence of inoculants and in presence or absence of calcareous - cut 2

\begin{tabular}{l|c|c|c|c}
\hline & $\begin{array}{c}\text { Com Inoculante } \\
\mathrm{kg} / \mathrm{ha}\end{array}$ & $\begin{array}{c}\text { Sem inoculante } \\
\mathrm{kg} / \mathrm{ha}\end{array}$ & $\begin{array}{c}\text { Com calcírio } \\
\mathrm{kg} / \mathrm{ha}\end{array}$ & $\begin{array}{c}\text { Sem calcário } \\
\mathrm{kg} / \mathrm{ha}\end{array}$ \\
\hline Ervilhaca & $1630,6 \mathrm{a} \mathrm{B}$ & $1625,2 \mathrm{a} \mathrm{B}$ & $1722,8 \mathrm{~b} \mathrm{~A}$ & $1859,8 \mathrm{a} \mathrm{A}$ \\
Comichão & $1952,1 \mathrm{a} \mathrm{A}$ & $1917,9 \mathrm{a} \mathrm{A}$ & $1745,9 \mathrm{a} \mathrm{A}$ & $1797,2 \mathrm{a} \mathrm{A}$ \\
\hline \multicolumn{5}{c}{63,06} \\
DMS
\end{tabular}

Médias seguidas pela mesma letra, maiúsculas na vertical e minúsculas na horizontal, não diferem pelo Teste de Tukey a $5 \%$.

Observa-se, na Tabela 7, que o cornichão apresentou maior produção de matéria seca que a ervilhaca, na presença e ausência do inoculante.

Quando consideradas as espécies ervilhaca e cornichão, observa-se que os tratamentos com inoculante e sem inoculante não diferiram entre si na produção de matéria seca.

Observa-se, na Tabela 7, que a ervilhaca apresentou maior quantidade de matéria seca na ausência de calcário, diferindo estatisticamente do tratamento com calcário. A produção de matéria seca na presença ou ausência de calcário, para a cultura do cornichão, não diferiu estatisticamente.

TABELA 8 - Produção de matéria seca (kg/ha) de duas espécies forrageiras, na presença e ausência de inoculante e presença e ausência de calcário - $2^{\circ}$ corte

Table 8 - Dry matter production ( $\mathrm{kg} / \mathrm{ha}$ ) of two forage species, Common Vetch and Birdsfoot Trefoil, in presence or absence of inoculants and in presence or absence of calcareous - cut 2

\begin{tabular}{l|c|c}
\hline & Com inoculante & Sem inoculante \\
\hline Com calcírio & 1722,8 a B & 1745,9 a A \\
Sem calcário & 1859,9 a A & 1797,2 a A \\
\hline DMS & & 63,06 \\
\hline
\end{tabular}

Médias seguidas pela mesma letra, maiúsculas na vertical e minúsculas na horizontal, não diferem pelo Teste de Tukey a $5 \%$. 
Os resultados apresentados na Tabela 8 mostram que a presença e a ausência de inoculante dentro da presença e ausência do calcário não foram estatisticamente diferentes.

Quando se considera a presença de inoculante, dentro do tratamento com e sem calcário, a maior produção de matéria seca foi alcançada para o tratamento sem calcário e diferiu estatisticamente do tratamento com calcário.

De acordo com Moraes (1995), a ervilhaca prefere solos com pH em torno de 6 a 6,5, mas produzem bem com $\mathrm{pH}$ até 5 , para o primeiro corte a ausência de calcário mostrou não ter sido um fator limitante para a cultura.

O cornichão é uma espécie pouco exigente em solo, porém responde bem à adubação e, principalmente, aos adubos fosfatados. A inoculação também é fator decisivo para obterem-se altas produções. A cultura mostra-se tardia nos primeiros meses, de cor esmaecida e baixa capacidade de rebrote na ausência de inoculação (MORAES, 1995). Para o tratamento em que se utilizou o cornichão, na presença de calcário e ausência de inoculante, não foram verificadas diferenças estatísticas com o melhor tratamento, mostrando que apesar da rusticidade da cultura em se desenvolver em solos pobres e tolerar $\mathrm{pH}$ inferior a 4,5, a correção do $\mathrm{pH}$ é uma prática que apresenta bons resultados na melhoria do desempenho produtivo da cultura.

A inoculação das sementes é uma prática absolutamente imprescindível, quando se deseja bons resultados na produção da ervilhaca (MORAES, 1995).

\section{CONCLUSÃO}

No primeiro corte, o teor de nitrogênio foi superior para a ervilhaca na presença de calcário e sem inoculante quando comparado ao cornichão.

A produção de matéria seca foi superior para a ervilhaca tanto na ausência como na presença de calcário, no primeiro corte.

A ervilhaca apresentou maior produção de matéria seca na ausência de inoculante, enquanto que para o cornichão a maior produção foi verificada na presença de inoculante.

No segundo corte, o teor de nitrogênio foi superior no tratamento com inoculante para o cornichão.

Para o cornichão, foi verificado maior teor de $\mathrm{N}$ na presença de calcário, no segundo corte.

No segundo corte, na ausência de calcário, o teor de $\mathrm{N}$ foi superior na presença de inoculante.

A produção de matéria seca do cornichão foi superior ao da ervilhaca tanto na presença quanto na ausência de inoculante, para o segundo corte.

A ervilhaca apresentou a maior produção de matéria seca na ausência de calcário, mas não diferiu daquela obtida para o cornichão.

No segundo corte, a produção de matéria seca foi superior na presença do inoculante e na ausência de calcário.

\section{REFERÊNCIAS}

ALCÂNTARA, P. B. et al. Plantas forrageiras: gramíneas \& leguminosas. 4. ed. rev. São Paulo: Nobel, 1992. $162 \mathrm{p}$.

COSTA, M. B. B. et al. Adubação verde no sul do Brasil. 2. ed. Rio de Janeiro: Universidade Rural Itaguaí, 1993. 346 p.

INSTITUTO AGRONÔMICO DO PARANÁ (IAPAR). Cartas climáticas do Estado do Paraná. Londrina: IAPAR, 1994. 49 p.

LENKEIT, W.; BECKER, M. Inspeção e apreciação de forrageiras. Lisboa: Ministério da Economia de Portugal, 1956. 152 p. (Boletim Pecuário, n. 2). 
MALAVOLTA, E. et al. Avaliação do estado nutricional das plantas: princípios e aplicações. Piracicaba: Associação Brasileira para Pesquisa da Potassa e do Fosfato, 1989. 201 p.

MARUN, F.; ALVES, S. J. Nutrição, adubação e calagem de forrageiras no Estado do Paraná. In: MONTEIRO et al. (Ed.). Forragicultura no Paraná. Londrina: Comissão Paranaense de Avaliação de forrageiras, 1996. p. 53-74.

MORAES, Y. J. B. Forrageiras: conceitos, formação e manejo. Guaíba, RS: Agropecuária, 1995.

OSAKI, F. Calagem e adubação. Campinas: Instituto Brasileiro de Ensino Agrícola, 1991. 526 p.

PAVAN, M. A.; OLIVEIRA, E. L. Manejo da acidez do solo. Londrina: IAPAR, 1997. 86 p.

PUPO, N. I. H. Manual de pastagens e forrageiras: formação, conservação, utilização. Campinas: Instituto campineiro de Ensino Agrícola. 1995.

THUNG, M. D. T.; OLIVEIRA, I. P. Problemas abióticos que afetam a produção do feijoeiro e seus métodos de controle. Santo Antonio de Goiás: EMBRAPA-CNPAF, 1998. 172 p.

UNIVERSIDADE FEDERAL DO RIO GRANDE DO SUL - UFRGS [site]. Rio Grande do Sul, 2005. Disponível em: <http://www.ufrgs.br>. Acesso em: 29 nov. 2005.

VILELA, H. Formação de pastagens. Agronomia o Portal da Ciência e Tecnologia. 2005. Disponível em: <http://www.agronomia.com.br/conteudo/artigos/artigos_formacao_pastagens.htm>. Acesso em: 01 dez. 2005.

Recebido em: 11/04/2007

Received in: 04/11/2007

Aprovado em: 31/07/2007

Approved in: 07/31/2007 